\title{
César Dávila Andrade: entre el poeta-sujeto y el sujeto empírico*
}

\author{
César Dávila Andrade: between poet-individual \\ and empirical-individual
}

\author{
Raúl Serrano Sánchez** \\ Universidad Andina Simón Bolívar, Sede Ecuador \\ raul.serrano@uasb.edu.ec
}

https://doi.org/10.32719/13900102.2018.43.4

Fecha de recepción: 9 febrero 2018

Fecha de aceptación: 23 abril 2018

$\Upsilon$ te quemaré en mi, Poesia!

En ladrillos de venas de amor, te escribiré empapándote profundamente.

Luego,

vendrá el sol y te extraerá con los colmillos

C. Dávila Andrade, "Poesía quemada".

\section{RESUMEN}

En este texto se examina la irrupción en el concierto de la vanguardia de la poesía ecuatoriana y latinoamericana de la década del 30 del siglo XX de un jovencísimo Dávila Andrade, con un poema cuya madurez y audacia no deja de asombrar a propios y extraños hasta la fecha; también el impacta que su temprano y lúcido ejercicio poético produjo en el medio social y cultural de su ciudad de origen, Cuenca, así como su condición en tanto un sujeto que siempre supo moverse en lo que el autor del artículo, citando a Eugenio Montale, define entre "el poeta-sujeto y el sujeto empírico".

* Este texto se leyó como parte del tributo a Cesar Dávila Andrade al celebrarse el centenario de su natalicio en 2018 en el Encuentro sobre Literatura Ecuatoriana Alfonso Carrasco Vintimila, organizado por la Universidad de Cuenca y la Carrera de Lengua, Literatura y Lenguajes Audiovisuales, entre el 20 y el 24 de noviembre de 2017.

** Ecuatoriano. Estudió comunicación social en la Universidad Central del Ecuador; realizó estudios de maestría, mención Literatura Hispanoamericana en la Universidad Andina Simón Bolívar, Sede Ecuador. Integra el Consejo Editorial de la revista Eskeletra y es editor de Kipus: 
PALABRAS CLAVE: Ecuador, vanguardia, poesía, César Dávila Andrade, sujeto, empírico. ABSTRACT

This text examines the irruption in the concert of the avant-garde of Ecuadorian and Latin American poetry of the 1930's decade of the 20th century by a very young Dávila Andrade, with a poem whose maturity and audacity does not cease to amaze both people and strangers to date; also the impact that his early and lucid poetic exercise produced in the social and cultural environment of his city of origin, Cuenca, as well as his condition as a subject that always knew how to move in what the author of the article, citing Eugenio Montale, defines as between "the poet-subject and the empirical subject".

KEY WORDS: Ecuador, vanguard, poetry, César Dávila Andrade, subject, empirical.

"LO QUE NECESITA un poeta es la búsqueda de una verdad puntual, no de una verdad general. Una verdad del poeta-sujeto que no reniegue la del hombre sujeto-empírico. Que cante lo que une al hombre a los demás hombres, pero que no niegue lo que lo separa y lo hace único e irrepetible" (Montale 1995, 23-24).

Estas palabras del poeta italiano Eugenio Montale datan de 1946 y sin duda son un acercamiento certero a lo que es la figura y obra de César Dávila Andrade, el Faquir (Cuenca, 1918-Caracas, 1967), uno de los referentes centrales de la poesía ecuatoriana y latinoamericana de la segunda parte del siglo XX. Un lugar que nadie le ha negado ni le podrá escamotear. Así lo revelan los testimonios y aproximaciones críticas de sus nuevos lectores. Baste como prueba lo que dicen los poetas, el cubano Jesús David Curbelo y el mexicano David Huerta (ambos encarnan a lectores y críticos de generaciones distintas), respecto a su obra en el prólogo y epílogo de la lograda edición Batallas del silencio (Poesía reunida) de Dávila Andrade lanzada en 2017 por Ediciones de la Lira.

$\mathrm{Al}$ retornar a la poesía o a la narrativa del Faquir (se compone de cuentarios tan ricos y complejos como Abandonados en la tierra, $1952 ; 13$ relatos,1955 y Cabeza de gallo, 1966), esa construcción nada planeada, da cuenta desde su primer poema del que se tiene noticia, "La vida es vapor", publicado en medio de la vorágine de las vanguardias latinoamericanas en

revista andina de letras y estudios culturales. Ha publicado los cuentarios: Las mujeres están locas por mí (1996, Premio “Ismael Pérez Pazmiño, Guayaquil, y Premio “Joaquín Gallegos Lara”, Municipio de Quito, 1997); Catálogo de ilusiones (2006) y Lo que ayer parecía nuestro (2015). La novela Un pianista entre la niebla (2016, Premio Único Ángel F. Rojas, CCE-Núcleo del Guayas). A finales de 2009 publicó el estudio En la ciudad se ha perdido un novelista. La narrativa de vanguardia de Humberto Salvador. Autor de varias antologías como Cuerpo adentro. Historias desde el clóset (Premio Manuela Sáenz, Municipio de Quito, 2014); El ensayo ecuatoriano de entre siglos (La Habana) y, conjuntamente con el escritor Andrés Echevarría, de la Antología Ecuador-Uruguay. Clásicos de la narrativa ecuatoriana-uruguaya 1900-1950 (Montevideo, 2018). Actualmente forma parte del Área de Letras y Estudios Culturales de la UASB, Sede Ecuador. 
el diario El Mercurio de Cuenca el 15 de julio de 1934; textos que nos participan de esa búsqueda de una "verdad puntual" que se irá ahondando y profundizando, complejizando, en uno y otro libro.

"La vida es vapor", está dedicado a Brumel, "Hélice de armonioso ciclón de la poesía vanguardista en el Ecuador". Se trata de su primo, el periodista Alberto Andrade y Arízaga, quien laboraba por entonces en el diario en el que se publicó el poema; texto que evidencia el conocimiento e interés de Dávila por los movimientos de vanguardia de su tiempo como el surrealismo, de cuyo influjo siempre supo sacar provecho.

"La vida es vapor", concluye con estos versos que no dejan de ser vanguardistas más allá de su momento histórico:

\section{Oigo cantar a las pirámides, unas canciones góticas... \\ Me estoy ahogando en un cacharro ilógico. \\ El universo se ha vuelto loco... En el Bosque}

de los insomnios, soy una hélice desorientada... (Dávila Andrade 2017, 25)

Lo peculiar de estos versos, es que se trata de un manifiesto de un poeta de 16 años, en el que todos los síntomas, los horizontes dislocados de la vanguardia transitan por él con una madurez que sin duda solo puede provocar (es lo que ocurrirá luego con otro de sus textos fundacionales) sospecha, tal cual le sucedió a su maestro del Instituto Normal Manuel J. Calle de Cuenca en 1930, quien luego de leer "Ecce homo" (poema del que no se tiene pistas y que Dávila escribe como parte de una tarea encomendada por el educador) se queda asombrado, desconcertado. El profesor pensó ligeramente que lo mejor era acusar al alumno de plagio y ponerle cero. Una conducta coherente, y que pone en evidencia que las sombras y fantasmas de la colonia seguían y continúan habitando entre nosotros.

¿Qué le sorprendió a aquel severo maestro de secundaria?

Lo que aún nos sigue sorprendiendo a sus lectores de la postmodernidad: que esa escritura, esa palabra poética cargada de tantos enigmas y códices secretos, solo puede generar sospechas, dudas de que pertenezca a un hombre que nació, como su Tocayo, el peruano Vallejo, en una ciudad recogida y periférica, en el seno de una familia en la que los liberales llevaban la voz sonante, aunque su padre Rafael era un conservador que como el padre de Kafka siempre estuvo esperando que su hijo "extraño" le ponga esa carta en la que todas las reconciliaciones, los malos entendidos y los abrazos postergados podrían ser posibles. Un encuentro que el escritor Jorge Dávila Vázquez ha hecho factible en su hermosa, intensa y conmovedora pieza teatral "Espejo roto" (1990), 
quizás una de las exploraciones más vitales a ese terreno cenagoso que es la interioridad, los otros lados y huecos de la biografía de un autor.

Sí, tal vez la reacción de aquel maestro normalista es clave para interpretar lo que significó para el joven poeta verse preso de un tiempo y un mundo en el que todos, los del establishment como los que eran sus cofrades, terminarían por tildarlo de "plagiador" e incluso, desde las miradas burguesas y pequeño burguesas, de "inútil, vago y raro". Hecho que lo llevó a emprender la marcha hacia ese exilio que en 1944 lo instala en Quito. En donde se vinculará a algunos poetas (Augusto Sacotto Arias, Ignacio Lasso, Pedro Jorge Vera, Alfredo Llerena y Humberto Vacas Gómez) que pertenecieron al grupo Élan, creado en la década del 30, y a Madrugada, formado por Galo René Pérez y al que se afilió el poeta y novelista Adalberto Ortiz; grupo en donde, al decir de Alejandro Carrión "lo recibieron con alborozo y le concedieron con indudable justicia honores de primera fila” (A. Carrión 1983, 134). 1944 es un año clave para la historia del país: el 28 de mayo ha estallado la revuelta democrático-burguesa conocida como La Gloriosa, que echó del poder a Alberto Arroyo del Río, aquel lúgubre plutócrata en cuya casa el joven Faquir había trabajado como valet. Un año en el que un intelectual como Benjamín Carrión hace realidad (es uno de los pocos logros de esa revuelta) la creación de la Casa de la Cultura Ecuatoriana. Institución en la que el autor de Mapa de América acoge, por mediación de algunos de los amigos del Faquir, como corrector de pruebas en la flamante editorial, al recién llegado.

Se cuenta que en cierta ocasión un par de patrióticas y creyentes señoras burócratas fueron a quejarse con el maestro Benjamín porque "ya no tenían vida con Don César", quien nunca llegaba a trabajar, y cuando lo hacía era, luego de sus épicas jornadas de bohemia, en estado calamitoso, que esto era injusto y que él, en tanto autoridad, debía ajustar cuentas con un empleado que lo estaba haciendo quedar mal, muy mal, doctor. Carrión, con la lucidez que lo caracterizaba, les respondió que les agradecía su preocupación y el dato delatorio, pero que les pedía de favor, es más, les ordenaba, que a partir de ese momento no perturbaran ni molestaran al poeta Dávila Andrade, porque ellas, como todos quienes pensaran igual, debían tener claro que la razón por la que él fue contratado era para que escribiera la mejor poesía que se ha escrito y se escribirá en este país. Y que las pruebas que él no ha corregido, un considerable número, se las llevaran a su despacho, que él se encargaría de revisarlas.

Como el maestro del Normal de Cuenca, Benjamín Carrión también tenía sus sospechas, aunque estas eran las mismas que años antes 
tuvo respecto a la obra de su coterráneo, uno de los nombres clave de la vanguardia ecuatoriana y latinoamericana del siglo XXX, Pablo Palacio, sobre quien, a raíz de su fallecimiento en un nosocomio de Guayaquil en 1947, el Faquir publica, en las páginas de la recientemente fundada revista Letras del Ecuador, "Palabras para el silencio de Pablo Palacio". Sin duda se trata de uno de los tributos más deslumbrantes y elocuentes que se hayan escrito sobre el autor de Un hombre muerto a puntapiés (1927) en su hora. La fuerza, la vitalidad, a más de dar cuenta de manera lúdica y alucinada de lo que era el mundo y la personalidad de Palacio, hacen de este texto una especie de pieza clave no solo para interpretar el orbe de signos en rotación de Dávila Andrade, sino del mismo hacedor de Vida del ahorcado (1932):

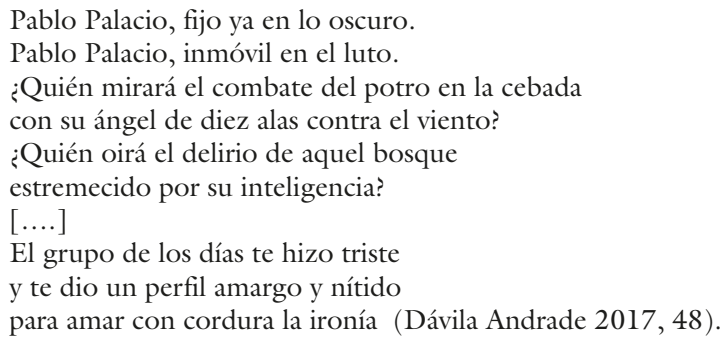

Esas sospechan, son las misma que Benjamín Carrión tendrá en torno a los cuentos de los bachilleres del Colegio Vicente Rocafuerte de Guayaquil que en 1930 publicaron Los que se van: cuentos del cholo i el montuvio; textos que el crítico intuyó, con ese olfato de lector agudo, que fundaban, igual que José de la Cuadra, Jorge Icaza y Humberto Salvador, la otra caligrafía de la nación, hecho que siempre generará a propios, más que a los extraños, ciertas sospechas. Tal es así que cuando el Faquir continúa en la construcción de ese mapa de signos de una patria que en algún lugar se le había extraviado, y envía al concurso de poesía de Diario El Universo de Guayaquil "Boletín y elegía de las mitas" (es el año 1959), el jurado, presidido -según anota Jorge Dávila Vázquez- por "el notable poeta cuencano César Andrade y Cordero, por sospechar que era de otro autor, que no contaba con sus simpatías" (Dávila Vázquez 1993, XXXIII), decidió otorgarle el segundo premio. Por su parte, el crítico Hernán Rodríguez Castelo, apunta sobre este hecho: "En efecto, parece que no se le otorgó el primer premio por creer que el poema pertenecía a G. h. Mata” (s.l., s.f., 170). Extraña, por decir lo menos, que los miembros del jurado, por razones extraliterarias hayan tomado una decisión que 
pone sobre el tape el hecho de haber desvirtuado - ¿por animadversión o prejuicio?- lo que es la escritura daviliana, que en relación a la literatura del maestro anarquista G. h. Mata (autor de novelas y poemarios indigenistascartelistas) no existe ningún tipo de convergencia o proximidad.

Es posible, desde otro ángulo, que a más de la razón anotada por Dávila Vázquez, los jurados, sin que esto sea una condena, hayan tomado, para no repetir al maestro del Normal, la precaución de darle ese lugar que de alguna forma era, otra vez, poner bajo sospecha al autor de un texto que ellos lo habrán intuido establecía, a partir de esa fecha una frontera en la poesía ecuatoriana y latinoamericana del siglo XX. Es un año cargado de cartas cruzadas: la violencia socialcristiana (nada nuevo por cierto en el país) decretada por Camilo Ponce Enríquez, a la sazón presidente de la república, contra los estudiantes y pobladores de Guayaquil, el estallido de la Revolución cubana y la instauración o el resurgir de amenazas que poco tiempo después podrían a tambalear los "valores" de la cultura y sociedad burguesa, eran parte del paisaje. No olvidemos que los otros premiados, y esto dice muchas cosas, eran Hugo Salazar Tamariz, también cuencano, y Hugo Mayo, quien nacido en Manta residía ya por varios años en Guayaquil.

Una tríada de nombres que, a su vez, ponían en evidencia un hecho: los códices de nuestra poesía, con el protagonista vital de las vanguardias de las décadas del 20 y 30, Hugo Mayo, obteniendo un tercer premio con "Caballo en desnudo" y un contemporáneo y coterráneo de Dávila Andrade, Salazar Tamariz, cuya propuesta ("Sinfonía de los antepasados") era una resonancia de las proclamas del vasto universo nerudiano, sin que esto le reste mérito al poema de Salazar que no deja de tener lo suyo. Claro que este premio también revelaba el hecho de que si los textos que flanqueaban al "Boletín" tenían sus logros, el del Faquir los desbordaba por que se constituía por si solo en un nuevo código poético. Esto es, en un lenguaje otro que daba cuenta de ese espejo enterrado que ha sido y es nuestra memoria. Un texto que se atrevía y desafiaba, sin calar en el cartelismo ni lo panfletario (o las evidentes deudas nerudianas, que aquí se licuan de manera lúcida), en ese lenguaje redescubierto de esa historia y memoria en las que como dice en uno de sus pasajes "y le encontré el pecho./ Era un hueso plano. Era un espejo. Me incliné. /Me miré, pestañeando. Y me reconocí. Yo, era él mismo!" (Dávila Andrade 2017, 187).

Estos logros y hallazgos, le dan razón al crítico Jorge Dávila Vázquez:

Este es, sin lugar a dudas, el mayor de los poemas de Dávila Andrade. Por 
plantear ciertos problemas de lectura, algunos lo han desdeñado, sin reparar en sus innumerables virtudes literarias ni en su calidad de obra maestra épico-lírica y testimonial, quizá la mayor de nuestra literatura (Dávila Vázquez 1993, XXXI).

Nada más subvertor -así lo habrá visto el jurado del concurso de El Universo- que ponernos, en tanto país y nación ante este boletín en el que se plantea, entre otras cosas, una relectura implacable, furibunda y desacralizadora, sin concesiones, de la historia patria, siempre falseada o escrita desde el poder hegemónico. Por ejemple, una de las ideas que se pone en cuestionamiento de manera ácida, es la del mestizaje como esa receta positivista de las supuestas y fatuas armonías con las que se escondía las atroces contradicciones sociales y políticas ante el acto de reconocernos en esas aguas turbias. Ese reconocimiento, el que nos empuja frente a "El boletín", era y es el asistir a la deconstrucción de una memoria en la que la ida de la patria (como matriz de unidad y escasa de contradicciones), desde las concepciones burguesas, con todo sus legados, eran sometidas a una requisitoria sistemática y crítica. De ahí que sorprenda que esos jurados, sin que esto implique justificarlos, hayan tenido el acierto y el valor de apostar por un texto que, lo sabemos, con o sin ese premio, no dejaría de ser y marcar la frontera que ha marcado en la tradición literaria del país y el continente; pero sucede que aconteció algo mucho más grave y complicado para las buenas conciencias, y es que esas visiones que deletrea "El boletín", se convirtieron en una cicatriz que desde entonces no deja de ser un aullido que a todos nos ha colocado como extraños o fantasmas que no encuentran ni encontramos sosiego para mirarnos en su química secreta.

En la escritura daviliana se cumple aquello que Octavio Paz anotaba en un artículo de 1967: "El falso poeta habla de sí mismo, casi siempre en nombre de los otros. El verdadero poeta habla con los otros al hablar consigo mismo" $(1988,72)$. Quizás ese "hablar con los otros" se expresa de manera legítima y contundente en la poesía daviliana, fluida y vitalmente como parte de ese "hablar consigo mismo" que aún en los textos que se han calificado de "herméticos", no dejan de ser la constancia de la palabra de un poeta que sabe que "el pez solo puede salvarse en el relámpago".

"Boletín y elegía de las mitas" es el culmine de la búsqueda de una verdad (solo un poeta de excepción sabe que toda verdad es una trampa, una ceremonia de inmolación), que ya se anuncia en textos como "Catedral salvaje" o en "Mi América india" (1951). El Faquir insistió entre uno y otro poema en esa "verdad puntual" de la que habla Montale, de ahí que huyera de las "verdades generales", incluso cuando canta a esos "mundos ingrávidos y sutiles" machadianos que tienen que ver con 
su álbum familiar o las encrucijadas del amor, el desamor, los amantes o la apariencia desvestida de los muertos y la muerte. El "Boletín", como Espacio me has vencido (1946), Arco de instantes (1959), se suma a lo que serán sus textos del periodo hermético: En un lugar no identificado (1962), Conexiones de tierra (1964), La corteza embrujada (1965), hasta llegar a Poesía del gran todo en polvo (1967), Materia real (1970) y Finale con Bettina, signos en rotación de, volviendo a Montale, "una verdad del poeta-sujeto que no reniega la del hombre sujeto-empírico".

Verdad que se ha cifrado en un canto que es el canto prohibido y oculto de los cuerpos con llagas, de la memoria escamoteada, de los espejos trisados, cuya vigencia y actualidad (la de su escritura), para lamento del asombrado maestro del Normal Manuel J. Calle, es parte de lo que el italiano Montale ha señalado: esa celebración del poeta-sujeto y del sujetoempírico que supo cantar "lo que une al hombre a los demás hombres".

Un ejercicio de la palabra poética (suma de visiones, "convulsión de una cacería") como de la del narrador, que no cabe duda lo hizo y lo hace al Faquir "único e irrepetible" en la literatura de su tiempo y en la de todos los tiempos del "Gran todo en polvo" (Dávila Andrade 2017, 280).

(Cuenca, 24 de noviembre 2017-Quito, 2018)

\section{Bibliografía}

Carrión, Alejandro. 1983 [1947]. "César Dávila Andrade o una isla rodeada de imposible". En Galería de retratos. Estudios sobre literatura ecuatoriana contemporánea. Quito: Banco Central del Ecuador.

Dávila Andrade, César. 2017. Batallas del silencio (Poesía reunida), edición: Cristóbal Zapata; organización de los textos: Jorge Dávila Vázquez; prólogo: Jesús David Curbelo, posfacio David Huerta. Cuenca: De la Lira Ediciones.

—. Boletín y elegía de las mitas [1960]. 2017. En Batallas del silencio (Poesía reunida), edición: Cristóbal Zapata; organización de los textos: Jorge Dávila Vázquez; prólogo: Jesús David Curbelo, posfacio David Huerta. Cuenca: De la Lira Ediciones.

__."Palabras para el silencio de Pablo Palacio" [1947]. 2017. En Batallas del silencio (Poesía reunida), edición: Cristóbal Zapata; organización de los textos: Jorge Dávila Vázquez; prólogo: Jesús David Curbelo, posfacio David Huerta. Cuenca: De la Lira Ediciones.

__. "El gran todo en polvo". 2017. Batallas del silencio (Poesía reunida), 
edición: Cristóbal Zapata; organización de los textos: Jorge Dávila Vázquez; prólogo: Jesús David Curbelo, posfacio David Huerta. Cuenca: De la Lira Ediciones, 280

Dávila Vázquez, Jorge. 2015. "Espejo roto" (1990). En A escena! Cinco piezas teatrales, Estudio introductorio de Raúl Serrano Sánchez. Quito: Libresa, Colección Antares.

Montale, Eugenio. 1995. “Intenciones (Entrevista imaginaria” (1946), en De la poesía, Valencia, Pre-textos: 23-24.

Paz, Octavio. 1988 [1967]. “Recapitulaciones”. En Corriente alterna. México: Siglo Veintiuno Editores.

Rodríguez Castelo, Hernán. s.f. Los de Elan y una voz grande. Clásico Ariel, Biblioteca de Autores Ecuatorianos, t. 90, s.1. 